\title{
PRINCIPAIS FATORES DE ABSENTEÍSMO NA ENFERMAGEM DE UM HOSPITAL DE MÉDIO PORTE DO SUL CATARINENSE
}

\author{
MAIN FACTORS OF ABSENTEEISM IN THE NURSING OF A MIDSIZE HOSPITAL SUL
}

\author{
CATARINENSE
}

Jonatan dos Santos Carlos da Silva ${ }^{1}$
José Otavio Feltrin $^{2}$
Magada Tessman Schwalm
Sonia Maria Correa

Recebido em: 01 dez. 2017

Aceito em: 10 jun. 2018

\begin{abstract}
RESUMO: Estudo com objetivo de conhecer os principais fatores de absenteísmo entre funcionários da equipe de enfermagem de um hospital geral do Sul Catarinense. É um estudo com abordagem quantitativa, retrospectiva, descritiva, com corte transversal, realizado por meio de pesquisa de dados secundários ou documental. A pesquisa foi realizada no período de outubro a novembro de 2017 no setor de Recursos Humanos (RH) do referido hospital onde foram utilizados os prontuários dos funcionários da equipe de enfermagem que estiveram afastado no primeiro semestre de 2017. Em todos os momentos que se discute a saúde do trabalhador é importante colocar que é necessário repensar a organização do trabalho, as estruturas e modelos gerenciais e organizacionais, investir em programas de promoção a saúde dos trabalhadores, em ambientes de trabalho saudáveis, em número de recursos humanos suficientes para a demanda de trabalho e, sobretudo, em valorização do trabalhador com jornada de trabalho e remuneração justa e digna.
\end{abstract}

Palavras-chave: Absenteísmo. Enfermagem. Trabalho.

ABSTRACT: Study in order to know the main factors of absenteeism among employees of the nursing staff of a general hospital in the South of Santa Catarina. Is a study with quantitative approach, retrospective, descriptive, with cross-section, accomplished through secondary data or documentary research. The survey was conducted in the period from October to November 2017 in the human resources (HR) of the hospital where they were used the medical records of employees of the nursing staff who were away in the first half of 2017. At all times that it comes to worker's health is important it is necessary to rethink the organisation of work, structures and managerial and organizational models, investing in programs to promote the health of workers, in healthy work environments, in number of sufficient human resources for work and, above all, in appreciation of the worker with working and fair and worthy compensation.

Keywords: Absenteeism. Nursing. Work.

\footnotetext{
${ }^{1}$ Enfermeiro - UNESC. E-mail: jonatasanto@hotmail.com.

2 Enfermeiro - Mestre em Saúde Coletiva. Universidade do Sul de Santa Catarina, UNISUL, E-mail: bimbauru@unesc.net.

${ }^{3}$ Enfermeira - Doutorado em Ciências da Saúde. Universidade do Extremo Sul Catarinense, UNESC, E-mail: magadatessman@gmail.com.

${ }^{4}$ Enfermeira - Especialização em Saúde Mental. Universidade do Extremo Sul Catarinense, UNESC, E-mail: soncorrea@yahoo.com.br.
} 


\section{INTRODUÇÃO}

Lorenzetti et al. (2014) diz que as atividades de gestão são constitutivas da prática da enfermagem, em especial do enfermeiro, desde a institucionalização da profissão, em meados do século XIX. Destaca-se nesse contexto do SUS a atuação dos enfermeiros em cargos de direção nos diversos níveis das instituições de saúde, desde a direção de unidades básicas de saúde, funções em nível central das esferas municipal, estadual e federal, bem como direção de órgãos de enfermagem em instituições hospitalares e coordenação de unidades assistenciais neste nível de atenção.

Nos dias atuais sabemos que a segurança do trabalho e saúde são indispensáveis quando a finalidade é conservar um ambiente de trabalho saudável e produtivo na organização. Sabemos que todas as empresas estão sujeitas a fiscalização de órgãos do governo, como as Delegacias Regionais do Trabalho (DRT'S) e o Instituto Nacional da Seguridade Social (INSS), bem como propensos de demandas na Justiça do Trabalho, tais como indenizações, ações criminais e cíveis. A importância da segurança deve ser valorizada todos os dias pelas empresas e seus colaboradores devido sua relevância e deve ser ainda ser praticada por todos que se preocupam com sua própria saúde. (SELL, 2012).

Segundo Oenning, Carvalho e Lima (2012), o absenteísmo é considerado como um período de ausência laboral que se aceita como atribuível a uma incapacidade do indivíduo, exceção feita para aquela derivada de gravidez normal ou prisão. A ausência ao trabalho por uma doença ou situação de saúde (gravidez) é validada com a apresentação de um atestado médico. Muitos estudos brasileiros se utilizaram de buscas documentais em arquivos médicos na tentativa de explicar o fenômeno absenteísmo.

O tema abordado para pesquisa foi escolhido de comum acordo entre o autor do projeto juntamente com o orientador, tendo em vista que a cada dia mais e mais profissionais estão se afastando do trabalho por motivos de doença, muitas vezes adquiridas dentro do ambiente de trabalho, seja ela física ou mental, assim como por não suportarem a sobrecarga de trabalho ocasionada pela falta de profissionais em seus setores, este e apenas uma das causas que levam ao afastamento.

A sobrecarga de trabalho pode ocasionar muitos problemas de saúde nos profissionais, principalmente na área da enfermagem que o profissional está lidando diretamente com o paciente. As pessoas têm a visão de que o técnico ou o enfermeiro não passam por complicações de saúde, mas todos são seres humanos possuem a possibilidade de ficarem doentes e sentirem dores, por isso a escolha deste tema de pesquisa. Será realizado um levantamento de dados que possa mostrar o quanto 0 profissional da enfermagem pode ser vulnerável quando se trata de saúde e doença, para saber o que pode estar ocasionando este problema que o faz ficar afastado do trabalho.

Os fatores de risco, presentes em ambientes, onde o trabalhador pode ser obrigado a manter um ritmo acelerado com a finalidade de garantir uma maior produção. (SINECOFI, 2010). 
Os principais fatores que levam os profissionais da área da enfermagem a se afastar do trabalho estão relacionados aos problemas de coluna e transtornos mentais. Os profissionais de enfermagem que tem registro de afastamento, são na maioria pessoas com mais de 45 anos, com tempo de atuação superior a 15 anos neste trabalho, a maioria trabalha em setores que requer cuidados de maior complexidade. A maior parte dos profissionais com afastamento por doença e em setores que exigem mais esforço físico dos profissionais onde o paciente encontrasse mais debilitado.

Com o intuito de conhecer os principais fatores que levam os profissionais de enfermagem a se afastarem do trabalho, tem-se como objetivo conhecer os principais fatores do absenteísmo entre os funcionários da equipe de enfermagem de um hospital do Sul de Santa Catarina.

\section{MÉTODO}

Estudo com abordagem quantitativa, retrospectiva, descritiva, com corte transversal, realizado por meio de pesquisa de dados secundários, conhecida como pesquisa documental. Foram quantificados dados obtidos através da análise de registros encontrados do primeiro semestre de 2017 , todas informações encontradas foram descritas passo a passo no decorrer da pesquisa, que servirão para futuras analises estatísticas para reduzir os índices de afastamento do trabalho.

Trata-se de um estudo com finalidade descritiva cujo método de abordagem a ser utilizado é o indutivo. O método de procedimento se deu com o uso de técnicas padronizadas de coleta de dados em um hospital do sul de Santa Catarina. O procedimento de pesquisa caracterizou-se como bibliográfico e de levantamento. A pesquisa teve como fonte primaria textos de referências nacionais enfatizando temas relacionados aos motivos de afastamento do trabalho. Estes textos servirão como base para o alcance dos objetivos citados.

A pesquisa foi baseada na busca documental quantitativo com instrumento para coleta de dados elaborado pelo autor do projeto. Além disto também buscou identificar os motivos específicos que levam cada um dos funcionários a buscarem atendimentos médicos na própria instituição. Contudo, foi feita uma amostragem não probabilística definido como público alvo os colaboradores do setor de enfermagem em um hospital do sul de Santa Catarina.

Richardson (1999) aponta ainda que nos estudos descritivos, o método de pesquisa quantitativo é frequentemente aplicado naqueles que procuram descobrir e classificar a relação entre as variáveis, assim como os que investigam a relação entre os fenômenos.

Pesquisa exploratória "permite ao investigador aumentar sua experiência em torno de um determinado problema. Consiste em explorar tipicamente a primeira aproximação de um tema e visa criar maior familiaridade em relação a um fato ou fenômeno." (LEOPARDI, 2002, p.119). 
O estudo foi desenvolvido em um hospital de médio porte, sendo um ponto estratégico e de fácil acesso para quem chega ao município, já que está inserido na porta de entrada da cidade. A pesquisa foi realizada nos setores de $\mathrm{RH}$ e Segurança do trabalho.

O hospital conta com um total de 132 funcionários, destes 76 profissionais são da área da enfermagem divididos em 16 enfermeiros, 55 técnicos de enfermagem e 5 auxiliares de enfermagem, os demais desempenham outras funções dentro da instituição.

O hospital não conta com SESMT, o setor de segurança do trabalho e composto apenas por uma técnica em segurança do trabalho e um médico do trabalho.

Por se tratar de um estudo com coleta de dados secundários não houve abordagem direta aos participantes, sendo os dados obtidos através dos registros de afastamento da equipe de enfermagem (prontuários). Fizeram parte da pesquisa todos os profissionais de enfermagem que estiveram afastados no período de janeiro a junho de 2017.

Para coleta de dados foi utilizado uma ficha de coleta elaborada pelo autor do projeto, foram utilizados registros de dados que comprovaram o afastamento dos profissionais da enfermagem tais como declarações, atestados concedidos por médicos, exames e/ou prontuário dos profissionais que estiveram afastados no primeiro semestre de 2017. Para identificar os funcionários da equipe de enfermagem foi solicitado auxílio de um (a) funcionário (a) do setor onde ocorreu a coleta dos dados.

Como critério de inclusão dos sujeitos praticantes da pesquisa utilizou-se: fazer parte do quadro de funcionários do hospital em questão; ser auxiliar ou técnico de enfermagem e enfermeiros; ter ficado afastado em algum período do primeiro semestre de 2017.

$\mathrm{Na}$ fase de análise de dados quantitativos, as informações foram quantificadas através do Microsoft Office Excel e apresentados por meio de análise quantitativa. Para análise dos dados coletados, realizou-se a tabulação dos dados obtidos através do instrumento de pesquisa, através da elaboração de tabelas e análise das respostas.

Por se tratar de um estudo quantitativo, a pesquisa não ofereceu riscos de confiabilidade e /ou privacidade, pois o risco será amenizado pela privacidade mantida; não sendo divulgados os dados relatados encontrados nos registros.

Não existem riscos presumíveis, desde que resguardados os valores éticos recomendados pela Resolução 510/2016 da Pesquisa com seres humanos; sendo garantido aos sujeitos participantes o anonimato e sigilo referente aos dados obtidos por meio de registros destes profissionais.

\section{APRESENTAÇÃO DOS RESULTADOS}

Após a aprovação da pesquisa pelo Comitê de Ética em pesquisa da UNESC sob o parecer 2.328.588/2017 foi iniciada a coleta de dados. Para tanto foi seguido um roteiro preestabelecido, para analisar o prontuário dos funcionários que estiveram afastados em 
algum momento no primeiro semestre de 2017 os quais foram apresentados pela técnica de segurança do trabalho da instituição. O número de afastamento previsto inicialmente foi de 18 funcionários. O roteiro seguido foi elaborado através dos objetivos específicos com as seguintes informações: idade, sexo, tempo de trabalho último afastamento, tempo de afastamento, motivo do afastamento, cargo que ocupa, setor que trabalha, turno de trabalho, formação profissional e município que reside.

\section{CARACTERIZAÇÃO DO PERFIL DOS PROFISSIONAIS ATUANTES NA ATENÇÃO HOSPITALAR}

De acordo com o quadro a seguir a faixa etária com maior índice de absenteísmo, destacou-se aquela entre 37 e 42 anos, o que equivale a $33,33 \%$ (6), seguindo-se as faixas de 55 e 60 anos, com 27,78\% (5), de 31 e 36 com 22,22\% (4), de 25 e 30 com 11,11\% (2) e por ultimo de 43 e 48 anos com 5,58\% (1).

Quadro 1 - Faixa etária dos profissionais afastados por doença no período de janeiro a junho 2017

\begin{tabular}{c|c|c}
\hline Faixa etária (anos) & Número & $\%$ \\
\hline 25 a 30 & 2 & 11,11 \\
31 a 36 & 4 & 22,22 \\
37 a 42 & 6 & 33,33 \\
43 a 48 & 1 & 5,56 \\
49 a 54 & 0 & 0 \\
55 a 60 & 5 & 27,78 \\
\hline Total & 18 & 100 \\
\hline
\end{tabular}

Fonte: Dados da pesquisa, 2017.

Ao comparar-se com estudos já realizados, pode-se citar Abreu e Simões (2009), que destacou que entre 30 e 49 anos, equivalente a $29,24 \%$ (112), seguindo-se as faixas de 40 a 49 anos, com 23,76\% (91), de 21 a 29 , com 22,98\% (88), de 50 a 59 anos, com $20,63 \%$ (79), e por último, de 60 a 67 anos, com 3,39\% (13 profissionais), podemos ver semelhanças entre os resultados encontrados pois indiferente do número de profissionais analisados entre uma pesquisa e outra destacamos que a maior faixa etária acometida foi aquela entre 30 e 49 anos, dando evidências que quanto mais avançada a idade do individuo menor será sua adaptação a mudanças na rotina de trabalho, e assim aumentando o sua ausência de suas funções.

Em relação ao perfil dos profissionais incluídos no estudo 100\% dos participantes eram do sexo feminino; a média de idade foi de 39 anos. Quanto ao nível de instrução $83,33 \%$ tem ensino médio completo e 16,7\% nível superior completo. O setor de atuação dos profissionais incluídos no estudo são: $44,44 \%$ trabalham na clínica médica; $27,8 \%$ trabalham no pronto-socorro; $16,7 \%$ trabalham na clínica cirúrgica, $5,55 \%$ trabalham no centro obstétrico e no faturamento. 
Quadro 2 - Perfil sócio demográfico dos profissionais de enfermagem atuantes na atenção hospitalar Características N(\%)ou mediana (mín-máx)

\begin{tabular}{lc}
\hline Gênero & \\
\hline Feminino & $100 \%$ \\
\hline Idade & $39(25-60)$ \\
\hline Escolaridade & \\
Nível Técnico & $15(83,33 \%)$ \\
Ensino Superior Completo & $3(16,67 \%)$ \\
& \\
Setor de Atuação & \\
Centro obstétrico & $1(1,55)$ \\
Pronto-Socorro & $5(27,8 \%)$ \\
Clínica Médica & $8(44,44 \%)$ \\
Clínica Cirúrgica & $3(16,7 \%)$ \\
Faturamento & $1(5,55 \%)$ \\
\hline Total & $18(100 \%)$ \\
\hline
\end{tabular}

Fonte: Dados da Pesquisa, 2017.

Atualmente, o absenteísmo relacionado às enfermidades/doenças alcançam altos índices nas organizações de trabalho, refletindo em altos custos tanto para as organizações, como para a sociedade. Em estudo indica que o Estado de São Paulo gasta por ano $\mathrm{R} \$ 290,5$ milhões com servidores públicos que faltam ao trabalho por motivos de saúde. (IWASSO apud FLORES et al., 2016).

Segundo Flores et al. (2016), as acentuadas transformações no mundo do trabalho têm suscitado uma crescente preocupação com relação à saúde do trabalhador como ação preventiva do absenteísmo. A presença do absenteísmo excessivo traz consequências desastrosas às organizações, refletindo sobremaneira na queda da produtividade e no consequente aumento dos custos da produção. Por outro lado, o fenômeno do absenteísmo, numa perspectiva sistêmica de análise das relações homem trabalho organização, pode ser tomado como sinal, e porque não dizer 'sintoma', de que também o trabalho, tal como se encontra em desenvolvimento no seio da organização, afeta o trabalhador de forma prejudicial, ou seja, a existência do absenteísmo em grau significativo denuncia a atuação negativa e destrutiva de um mal estar e, portanto, prejuízos que ocorrerão numa via de mão dupla: atingindo primeiramente o corpo e o psiquismo do trabalhador e a já citada produtividade organizacional secundariamente. No entanto, devese considerar que o trabalho também pode significar sofrimento psíquico, alienação, comprometimento da saúde física e mental do trabalhador.

Segundo Maslach e Leiter (1999 apud FLORES et al., 2016), as principais causas do acentuado desgaste físico e mental dos trabalhadores são:

a) O excesso de trabalho, que os obriga a se desdobrarem e aumentar significativamente o ritmo de trabalho;

b) Políticas organizacionais que reduzem a autonomia e a liberdade do trabalhador;

c) O trabalho executado não ser satisfatório e recompensado adequadamente; 
d) O aumento da competitividade das pessoas dentro das organizações e decorrente diminuição da solidariedade entre elas, gerando um aumento de conflitos internos e empobrecendo o verdadeiro sentido do trabalho em equipe;

e) A falta de equidade, ou seja, as pessoas não são respeitadas e não tem o reconhecimento necessário;

f) A presença de conflitos de valores, o qual leva a um desequilíbrio entre as exigências do trabalho e os princípios pessoais e éticos.

Os efeitos do absenteismo nas instituições são negativos, pois devido a este fator, ocorre grande queda na produtividade do trabalho. (PENNATTI FILHO; ZAGO; CALHAS, 2006; FLORES et al., 2016).

Como pode-se observar no quadro anterior existe um predomínio do sexo feminino na área da enfermagem, estes estão expostos diariamente a condições estressantes e exaustivas no trabalho, podendo apresentar maior risco do que se fossem comparados a profissionais do sexo masculino. Entretanto este trabalho evidencia como limitação para confirmação desta hipótese, tendo em vista que não aparecem profissionais do sexo masculino com registros de afastamento de suas atividades, assim havendo uma necessidade de outras investigações que possam confirmar esse aspecto.

No hospital pesquisado $11(61,11 \%)$ residem em lçara e 07 (38, 89\%) residem em Criciúma.

Quanto ao nível de qualificação dos profissionais, observamos que entre técnicos de enfermagem e enfermeiros, a prevalência de trabalhadores afastados e maior entre técnicos de enfermagem totalizando $88 \%$ dos profissionais afastados do trabalho.

Este dado é um tanto quanto preocupante pois segundo estudo realizado em um hospital universitário de Goiânia - GO, por Marques et al. (2015), esses profissionais representam o maior contingente da força de trabalho da equipe de enfermagem. Suas ausências comprometem a assistência prestada e, consequentemente, desestruturam a equipe por gerar sobrecarga de atividades aos demais trabalhadores.

Quando o profissional de saúde fica exposto de forma prolongada ao estresse ocupacional é necessário atentar para a síndrome de desgaste profissional, em que o profissional poderá apresentar altos níveis de exaustão emocional, em que ocorre redução de recursos emocionais dos profissionais e esta condição podem apresentar menor rendimento profissional. (KHAMISA; PELTZER; OLDENBURG, 2013).

Em relação ao setor que cada profissional atua dentro da instituição estudada, podemos observar que 44,44\% atuam na clínica médica, 27,8\% no pronto Socorro, 16,7\% na clínica cirúrgica, e 1,55\% no centro obstétrico e faturamento. Como pode-se constatar a prevalência maior de atuação e também tem o maior índice de afastamento, são nos setores da clínica medica com $87,5 \%$ dos afastados são técnicos de enfermagem e 12,5\% são enfermeiros e no pronto Socorro são $80 \%$ técnicos de enfermagem e $20 \%$ enfermeiros.

Pode-se entender que os elevados índices de afastamento por esses profissionais 
que dedicam se incansavelmente no cuidado aos pacientes, alguns fatores de risco que podem ser levados em conta são, as intensas e ininterruptas jornadas de trabalho que exigem tanto a parte física como mental dos trabalhadores, e as sobrecargas de trabalho uma vez já citado anteriormente muitas vezes a demanda de pacientes é excessiva, muito além da quantidade de profissionais que possam suprir essas necessidades.

Quadro 3 - Tempo de trabalho, turno, tempo de afastamento e cidade em que reside afastados dos profissionais afastados

\begin{tabular}{c|c|c|c}
\hline Tempo de Trabalho. & Turno de Trabalho. & Tempo de Afastamento. & Município de Residência \\
\hline 26 & Noturno & 2 & Criciúma \\
\hline 10 & Integral & 5 & Içara \\
\hline 16 & Noturno & 120 & Içara \\
\hline 2 & Vespertino & 7 & Criciúma \\
\hline 1 & Integral & 1 & Criciúma \\
\hline 7 & Noturno & 1 & Criciúma \\
\hline 1 & Integral & 7 & Criciúma \\
\hline 1 & Integral & 1 & Içara \\
\hline 26 & Matutino & 10 & Criciúma \\
\hline 3 & Vespertino & 65 & Içara \\
\hline 26 & Matutino & 3 & Içara \\
\hline 5 & Vespertino & 15 & Içara \\
\hline 26 & Matutino & 5 & Içara \\
\hline 6 & Noturno & 120 & Içara \\
\hline 5 & Vespertino & 10 & Içara \\
\hline 3 & Vespertino & 7 & Criciúma \\
\hline 1 & Integral & 1 & Içara \\
\hline 5 & integral & 120 & \\
\hline Fona & & & \\
\hline
\end{tabular}

Fonte: Dados da pesquisa, 2017.

A idade também foi um fator relevante, contou com uma amostra de profissionais com idade entre 25 e 60 anos, e com tempo de experiência 1 a 26 anos de trabalho, assim como diversos estudos realizados entre trabalhadores da enfermagem.

Como pode-se observar no quadro acima, em relação ao turno de atuação podese destacar que $33,33 \%(6)$ dos profissionais ausentes do trabalho atuam no período integral, $27,77 \%$ (5) atuam no período vespertino, 16,67\% (3) atuam no período matutino e $22,22 \%$ (4) no período noturno. Podemos destacar que a prevalência de afastamento do trabalho é predominante nos profissionais que atuam no turno matutino e vespertino respectivamente.

Em comparação com pesquisa realizada por Abreu e Simões (2009), as ausências em relação ao turno de trabalho, observou-se que $153(40,91 \%)$ profissionais estão lotados no turno da noite; 130 (34,76\%) estão no turno da manhã; 93 (24,87\%) encontram-se no turno da tarde e $7(1,87 \%)$ realizam horário administrativo.

Tendo em vista que a amostra do presente estudo foi relativamente pequena comparado com os resultados apresentados por Inoue et al. (2008) apud Abreu e Simões (2009) em estudos realizados em um hospital universitário revela que os profissionais do período noturno se ausentam com maior frequência do trabalho por motivos de alterações 
fisiológicas decorrentes da falta de sincronismo entre seu ritmo circadiano e o prolongamento do período de vigília. Estas alterações orgânicas predispõem ao comprometimento da capacidade de concentração e, além disso, interferem no convívio familiar, em razão da incompatibilidade de horário.

\section{MOTIVOS DE AFASTAMENTO}

Em relação aos motivos de afastamento relacionado a licença gestacional; ameaça de aborto e pós parto ocorreu em $33,32 \%$ dos casos; $11,11 \%$ procedimento odontológico; $11,10 \%$ problemas ortopédicos; $5,55 \%$ problemas cardíacos; conjuntivite; náusea e vomito; gripe; transtorno afetivo bipolar, episódios depressivos, ansiedade generalizada.

Destaca-se que $16,66 \%$ dos casos de afastamento do trabalho da equipe de enfermagem do Hospital pesquisado estão sem identificação; demonstrando a subnotificação.

Quadro 4 - Motivo do afastamento $(\mathrm{N}=18)$

\begin{tabular}{|c|c|c|}
\hline Motivos de Afastamento & $\mathbf{N}$ & $\%$ \\
\hline Angina instável - Cateterismo & 1 & 5,55 \\
\hline Luxação & 1 & 5,55 \\
\hline Dor no pé direito & 1 & 5,55 \\
\hline Transtorno afetivo bipolar, episódios depressivos, ansiedade generalizada & 1 & 5,55 \\
\hline Conjuntivite & 1 & 5,55 \\
\hline Pós parto fraqueza & 1 & 5,55 \\
\hline Gripe & 1 & 5,55 \\
\hline Náusea e vomito & 1 & 5,55 \\
\hline Procedimento odontológico & 2 & 11,11 \\
\hline Ameaça de aborto & 2 & 11,11 \\
\hline Licença gestação & 3 & 16,66 \\
\hline Sem identificação & 3 & 16,66 \\
\hline Total & 18 & $100 \%$ \\
\hline
\end{tabular}

Fonte: Dados da pesquisa, 2017.

A angina instável com a necessidade de cateterismo foi identificada como motivo de afastamento em $5,55 \%$ dos casos, em profissional do sexo feminino, 56 anos; técnica de enfermagem; tempo de trabalho 3 anos.

Em pesquisa de Santos e França (2013) identificou que o estresse e o sedentarismo são importantes fatores de risco para doença arterial coronariana e que acometem cerca de $50 \%$ dos envolvidos, sendo estes pertencentes à equipe de enfermagem.

A doença arterial coronariana é considerada um problema de saúde grave com alta morbidade e mortalidade; sendo relevante a implementação de programas de promoção a saúde com adoção de hábitos saudáveis e ações preventivas para evitar complicações. (SANTOS; FRANÇA, 2013).

Segundo Custodio et al. (2011) existe elevados índices de morbimortalidade nos profissionais da saúde, em especial as doenças crônico-degenerativas, a exemplo das 
cardiovasculares, sendo importante o desenvolvimento de ações centradas na saúde do trabalhador.

As ausências do trabalho relacionadas a problemas ortopédicos como luxação e dores no pé aparecem com $5,55 \%$ cada uma totalizando $11,1 \%$ das causas de afastamento do trabalhador.

Marques et al. (2015) relata que devido às características do trabalho desenvolvido pela equipe de enfermagem e o grande risco de desenvolver doenças osteomusculares, é necessário adequar o ambiente de trabalho, visando amenizar os riscos para a saúde desse trabalhador.

Em relação às doenças osteomusculares, a Organização Mundial de Saúde (2007) designou o decênio de 2000 a 2010 como a década do osso e da articulação, devido ao número crescente das doenças e lesões osteoarticulares que incidem na população mundial. Estima-se que, estas serão a causa de maiores gastos com saúde e um dos motivos mais frequentes de absenteísmo laboral e de invalidez permanente.

Segundo Lima et al. (2014) as condições de trabalho têm impacto na capacidade de trabalhar e a dor sentida pelos trabalhadores é um dos fatores nocivos para sua saúde física e mental. Assim, relacionar a dor às características sócio-demográficas e trabalhistas dos trabalhadores pode fornecer subsídios para as mudanças a serem feitas, adaptando o ambiente de trabalho de acordo com as condições dos profissionais que trabalham nela. $A$ dor está desabilitando. Os trabalhadores que sofrem de distúrbios musculoesqueléticos muitas vezes são classificados no ambiente de trabalho como queixosos. No entanto, devese levar em conta que, geralmente, o diagnóstico desses distúrbios é clínico, uma vez que não apresentam características externas. Portanto, é importante considerar a possibilidade de uma participação ativa e coletiva de trabalhadores em luta por melhores condições de trabalho como prioridade.

Os transtornos mentais estão entre os principais causadores do afastamento do trabalho, sendo diversos os motivos que levam ao adoecimento metal. Mas decorrer deste estudo ficou evidenciado perante os registros encontrados que o afastamento por doença metal não foi um fator predominante entre as doenças encontradas apenas 1,55\% dos funcionários estiveram ausentes do trabalho por este motivo.

Santana et al. (2016), em estudo realizado em um hospital do sul do Brasil entre os trabalhadores de saúde $18 \%$ foram entre profissionais de enfermagem, cuja prevalência ocorreu entre trabalhadores do sexo feminino, correspondente a 76,36\%. A faixa etária predominante foi entre 21 a 30 anos, totalizando 34,54\%. Quanto às causas de afastamento, o estudo nos permitiu observar uma frequência significativa de episódios depressivos, totalizando $52,72 \%$ dos transtornos mentais. A segunda maior ocorrência foi evidenciada para os transtornos ansiosos com 18,18\% da amostra.

Quando o profissional de saúde fica exposto de forma prolongada ao estresse ocupacional é necessário atentar para a síndrome de desgaste profissional, em que o profissional poderá apresentar altos níveis de exaustão emocional, em que ocorre redução 
de recursos emocionais dos profissionais e a esta condição podem apresentar menor rendimento profissional. (KHAMISA; PELTZER; OLDENBURG, 2013).

De acordo com Silva Junior e Fischer (2015), uma publicação conjunta da Organização Internacional do Trabalho (OIT) e da Organização Mundial da Saúde (OMS) chamou a atenção para a relevância da relação entre fatores psicossociais no trabalho e repercussão sobre a saúde dos trabalhadores.

Segundo a Organização Mundial da Saúde (1993) que publica o CID-10, é recomendada a utilização do termo transtorno em substituição a expressões como doença ou enfermidade, que causam polêmica. Trata-se do CID-10 de um documento técnico da área que padroniza a nomenclatura utilizada pelos profissionais da área de saúde. Assim, transtorno é utilizado para "indicar a existência de um conjunto de sintomas ou comportamentos clinicamente reconhecíveis, associados, na maioria dos casos, a sofrimento e interferência com funções pessoais." (OMS, 1993, p.5). Existem diversos tipos de transtornos, destacando-se para este estudo os transtornos do humor (afetivos), que incluem as manias, a bipolaridade, depressão e outros; transtornos neuróticos, relacionados ao estresse e somatoformes, onde estão as fobias, o pânico, a obsessão, a compulsão e o estresse grave; síndromes comportamentais associadas a perturbações fisiológicas e fatores físicos, onde são encontrados os transtornos alimentares, os transtornos do sono, disfunções sexuais e abusos de substâncias que não produzem dependência. (OMS, 1993).

Segundo Bosaipo, Borges e Jurema (2016) o Transtorno Bipolar (TB), também conhecido como 'transtorno afetivo bipolar' e originalmente chamado de 'insanidade maníaco-depressiva', é uma condição psiquiátrica caracterizada por alterações graves de humor, que envolvem períodos de humor elevado e de depressão (polos opostos da experiência afetiva) intercalados por períodos de remissão, e estão associados a sintomas cognitivos, físicos e comportamentais específicos.

De com o HOSP (2017) a conjuntivite também é motivo de afastamento em 5,55\% dos casos, uma doença que se caracteriza pela inflamação da conjuntiva, causada por agentes tóxicos, alergias, bactérias ou vírus. A conjuntiva é a membrana transparente que recobre o globo ocular e a parte interna da pálpebra. A conjuntivite viral é altamente contagiosa, frequente no verão, e apesar de não ser grave provoca muito incômodo e alguns cuidados devem ser tomados para que não se transforme em epidemia. Geralmente compromete os dois olhos, não necessariamente ao mesmo tempo, sendo o contagio feito pelo contato direto com a pessoa doente ou objetos contaminados. Esta contaminação ocorre com maior facilidade em ambientes fechados como escolas, creches e ônibus. Os principais sintomas da conjuntivite são: olho vermelho e lacrimejante; inchaço nas pálpebras; intolerância à luz; visão embaçada; visão borrada.

A secreção da conjuntivite viral é mais esbranquiçada, em pequena quantidade e demorando aproximadamente 15 a 20 dias para desaparecer com tratamento adequado. A secreção da conjuntivite bacteriana é mais amarelada e abundante. Demorar de 5 a 7 dias para desaparecer com tratamento adequado. 
Não existe tratamento específico para conjuntivite viral. Para diminuir os sintomas e o desconforto pode-se utilizar soro fisiológico gelado e compressas sobre as pálpebras, limpar os olhos com frequência, ou ainda, usar colírios lubrificantes e lágrimas artificiais.

Ainda assim, algumas medidas podem ser tomadas para se evitar a propagação da conjuntivite viral:

Lavar as mãos com frequência;

Não colocar as mãos nos olhos para evitar a recontaminação;

Evitar coçar os olhos para diminuir a irritação da área;

Não usar medicamentos (pomadas, colírios) sem prescrição (ou que foram indicados para outra pessoa);

Lavar as mãos antes e depois do uso de colírios ou pomadas;

Ao usar, não encostar o frasco de colírios ou da pomada no olho;

Evitar a exposição à agentes irritantes (fumaça) e/ou alégenos (pólen) que podem causar a conjuntivite;

Não usar lentes de contato enquanto estiver com conjuntivite;

Não usar lentes de contato se estiver usando colírios ou pomadas;

Não compartilhar lençóis, toalhas, travesseiros e outros objetos de uso pessoal de quem está com conjuntivite;

Não usar cosméticos de outras pessoas;

Usar óculos de mergulho para nadar, ou óculos de proteção em casos de trabalho com produtos químicos;

Evitar nadar em piscinas sem cloro ou em lagos.

É importante que haja o acompanhamento do oftalmologista para um diagnóstico preciso e tratamento adequado. A conjuntivite bacteriana deve além desses cuidados, usar colírios e antibióticos prescritos somente pelo oftalmologista.

Em estudo realizado na Universidade Federal da Bahia por Cruz, Kalil e Nunes (2013) há algum tempo foi estabelecida uma relação lógica entre a saúde do trabalhador e a sua qualidade de vida. A saúde bucal, por ser imprescindível à saúde geral do trabalhador, torna-se essencial neste contexto. $O$ benefício da licença para tratamento de saúde é previsto na Lei no 8.112/90, que dispõe sobre o regime jurídico dos servidores públicos civis da União, das autarquias e das fundações públicas federais.

Em relação aos motivos odontológicos, de acordo com o estudo feito por Martins et al. (2005), as ausências tiveram pouco peso sobre o total de faltas por motivo de doença, além de provocar o afastamento do trabalhador por um período menor. As variáveis idade, sexo, função e regime empregatício influenciaram na ocorrência do absenteísmo ao trabalho. A disponibilidade dessas informações deverá ser muito importante, pois, visto as 
inúmeras variáveis envolvidas, facilitarão a tomada de decisões das distintas estratégias para sua prevenção.

Martins et al. (2005) ainda diz que os atestados médicos e odontológicos são os únicos instrumentos legais que servem para abonar as faltas ao trabalho por motivo de doença e assegurar o pagamento dos respectivos salários, desde que apresentem a codificação da enfermidade - CID (NOGUEIRA; LAURENTI, 1975 apud MARTINS et al., 2005), conforme especificado por Acórdão do Tribunal Superior do Trabalho (TST) no dissídio da categoria e estatuto municipal. (ARAÇATUBA, 2002; CARRION, 1994; SIME, 2000 apud MARTINS et al., 2005).

No decorrer da pesquisa estiveram em destaque os fatores de afastamento relacionados a saúde da mulher, destes 5,55\% alegaram fraqueza no pós parto, 11,11\% estiveram afastados por motivos referentes ao aborto e $16.66 \%$ por gestação, totalizando $33,32 \%$ dos profissionais da enfermagem ausentes do trabalho por motivos relacionados a saúde da mulher.

Para Costa, Santos e Netto (2014) a perda gestacional recorrente da gravidez ou o abortamento de repetição são definidos como a interrupção espontânea e consecutiva de três ou mais gestações, antes da $22^{a}$ semana. $O$ atendimento a mulheres com perdas gestacionais de repetição, sejam precoces ou tardias, representa um desafio, em função dos múltiplos fatores envolvidos na etiologia dos insucessos gestacionais.

Como podemos observar as causas do absenteísmo são variadas, tendo em vista que em alguns casos podemos ainda encontrar registro incompletos pode observar no quadro acima descrito, deste modo podemos citar que $16,66 \%$ dos afastamentos na enfermagem estavam 'sem identificação' não por falta de diagnostico mas sim por falta de um registro completo em relação ao afastamento de suas funções na instituição, se remeterem à pesquisa, segundo Chiavenato apud Cobêro e Godoy (2014), em que as ausências estão relacionadas à: doença comprovada; doença não comprovada; razões diversas, familiar; atrasos involuntários; faltas voluntárias por motivos pessoais; dificuldades e problemas financeiros; problemas de transporte; baixa motivação; supervisão precária; políticas inadequadas da organização.

Cobêro e Godoy (2014) afirmam que todas as causas de absenteísmo têm que ser diagnosticadas e deve haver uma ação coordenada da supervisão, para tentar reduzir os atrasos e ausências do pessoal. Os autores explicam que para alcançar os objetivos do levantamento do absenteísmo, as empresas utilizam um ou mais índices para verificar as ausências. Esses índices podem ser mensais, trimestrais, semestral ou anual, dependendo da cultura da empresa e da prioridade estabelecida pela mesma.

Considera-se que a notificação correta e completa dos motivos de afastamento são essenciais para o conhecimento e identificação dos casos e implementação de programas voltados à saúde do trabalhador.

Para Rodrigues e Araújo (2016), observa-se que há muito a se fazer em termos de se combater o absenteísmo, principalmente na forma de como o profissional de saúde é 
tratado. Pontuamos que deve haver uma maior valorização profissional por meio da boa remuneração e oferta de um ambiente de trabalho mais adequado às necessidades de serviços realizados. Assim, os profissionais diminuem o número de tarefas e possíveis acidentes de trabalho devido à exaustão física e mental, vindo a adoecer menos e a reduzir os índices dessa problemática.

Para Mininel (2013) esse dado é de extrema importância para a instituição, pois possibilita o reconhecimento dos indivíduos que têm apresentado queixas e afastamentos recorrentes, favorecendo a avaliação individual dos casos e a proposição das intervenções coletivas necessárias.

\section{CONSIDERAÇÕES FINAIS}

Este estudo buscou conhecer os principais fatores de absenteísmo entre funcionários da equipe de enfermagem de um hospital geral do Sul Catarinense. Os resultados encontrados mostraram que todos os afastamentos foram devido a problemas de saúde, portanto absenteísmo doença. Aparentemente o número de afastamento não foi expressivo, mas relacionando ao número total de funcionário houve $13.63 \%$ de afastamento no primeiro semestre de 2017 , se relacionarmos ao número total da equipe de enfermagem o número de afastamento foi de $23.68 \%$. Os problemas de saúde encontrados foram variados, sendo que o maior índice de afastamentos destas trabalhadoras foi por motivo de gestação e suas complicações e puerpério. As hipóteses na sua maioria não foram confirmadas tendo em vista que não foi encontrado nenhum problema de coluna, apenas um caso de transtorno mental, o maior número de afastamento foram mulheres com idade entre 25 a 43 anos, que trabalham na clinica médica. $O$ turno de trabalho com maior índice de afastamento foi o matutino/vespertino (9 horas de trabalho diário) e $66.66 \%$ das trabalhadoras que se afastaram tinham menos de 15 anos de trabalho.

Os profissionais afastados são todos do gênero feminino com idade entre 25 a 60 anos. $44.44 \%$ (08) das funcionárias afastadas trabalham na clinica médica, 83.33\% (15) são técnicas de enfermagem, $33.33 \%$ (6) trabalham nove horas diárias (turno matutino e vespertino). Com relação ao motivo do afastamento $33.33 \%$ (6) trabalhadoras foi por motivo de gestação e suas complicações e puerpério. O maior número de dias de afastamento foram 120 dias (licença maternidade 22.22\%) e 65 dias (Transtorno Afetivo Bipolar 5.56\%).

$\mathrm{O}$ trabalho de enfermagem confronta-se com limitações e desafios diários, e diversos fatores de saúde ocasionam o afastamento do profissional do trabalho por determinado tempo, seja ele programado ou não. Os resultados encontrados evidenciam a necessidade de medidas preventivas e assistenciais voltadas aos trabalhadores, que por algum motivo buscam como alternativa o afastamento do trabalho, o desgaste físico e metal como pode ser mostrado na pesquisa, não deve ser encarado como fraqueza pessoal, falta de caráter, de forca de vontade, etc, deve ser encarado como um problema de saúde como outro qualquer. 
Principalmente na enfermagem que a demanda de pacientes e muito maior do que o quadro de funcionários disponíveis para o cuidado dos pacientes, as exaustivas horas trabalhadas, a sobrecarga de trabalho. investir em programas de promoção a saúde dos trabalhadores, em ambientes de trabalho saudáveis, em número de recursos humanos suficientes para a demanda de trabalho e, sobretudo, em valorização do trabalhador com jornada de trabalho e remuneração justa e digna. No que se referem às limitações do estudo ainda existem falhas na alimentação do banco de dados como a falta de informações sobre qual o motivo que levou o profissional ao afastamento do trabalho.

Sugerimos que outros estudos sejam realizados nesta instituição, incluindo profissionais de outras áreas que atuam no hospital.

\section{REFERÊNCIAS}

ARAÇATUBA. Prefeitura. Estatuto - Lei no 3774. 2002. Disponível em <www.aracatuba.sp.gov.br>. Acesso em: 6 out. 2017.

BRASIL. Ministério da Saúde. Resolução 510/2016. Disponível em: http://conselho.saude.gov.br/resolucoes/2016/reso510.pdf. Acesso em: 1 dez. 2017.

CARRION, V. Nova jurisprudência em direito do trabalho. São Paulo: Revista dos Tribunais, 1994.

COSTA, Olivia Lúcia Nunes; SANTOS, Eliane Menezes Flores; NETTO, Eduardo Martins. Aspectos epidemiológicos e obstétricos de mulheres com perdas recorrentes da gravidez em uma maternidade pública do Nordeste do Brasil. Rev. Bras. Ginecol. Obstet., Rio de Janeiro, v.36, n.11, p.514-518, nov. 2014. Disponível em:

<http://www.scielo.br/scielo.php?script=sci_arttext\&pid=S0100$72032014001100514 \&$ Ing=en\&nrm=iso >. Acesso em: 31 out. 2017. http://dx.doi.org/10.1590/S0100-720320140005007

CUSTODIO, Ires Lopes et al. Perfil sociodemográfico e clínico de uma equipe de enfermagem portadora de Hipertensão Arterial. Rev. bras. enferm. Brasília, v.64, n.1, p.18-24, fev. 2011. Disponível em:

<http://www.scielo.br/scielo.php?script=sci_arttext\&pid=S003471672011000100003\&lng= en\&nrm=iso>. Acesso em: 17 out. 2017. http://dx.doi.org/10.1590/S003471672011000100003.

HOSP. Hospital de Olhos de São Paulo. Conjuntivite. 2017. Disponível em: <http://www.hospitaldeolhos.net/especialidades-conjuntivite.asp>. Acesso em: 6 nov. 2017.

LEOPARDI, M. T. Metodologia da pesquisa na saúde. Santa Maria, RS: Pallotti. 2002.

LIMA, Ana Cláudia Soares et al. Fatores associados à dor musculoesquelética em trabalhadores de enfermagem hospitalar. Revista Enfermagem UERJ. Rio de Janeiro, v.22, n.4, p.526-32, jul/ago. 2014. Disponível em: <www.epublicacoes.uerj.br/index.php/enfermagemuerj/article/view/4265/11647>. Acesso em: 04 nov. 2017. 
MARTINS, Ronald Jefferson et al. Absenteísmo por motivos odontológico e médico nos serviços público e privado. Rev. bras. saúde ocup. São Paulo, v.30, n.111, p.09-15, jun. 2005. Disponível em <http://www.scielo.br/scielo.php?script=sci_arttext\&pid=S0303$76572005000100002 \&$ Ing $=$ pt\&nrm=iso $>$. Acesso em: 02 nov. 2017. http://dx.doi.org/10.1590/S0303-76572005000100002.

NOGUEIRA, D. P; LAURENTI, R. Absenteísmo por doença em mulheres. Revista de Saúde Pública. São Paulo, v.9, n.3, p.393-399. 1975.

OMS. Organização Mundial da Saúde. Classificação de transtornos mentais da CID10. Porto Alegre: Artmed, 1993.

. Década do osso e da articulação: movimento articular. 2007. Disponível em: <http://www.osteoartrose.com.br/tm_decada.php>. Acesso em: 02 nov. 2017.

PEREIRA, Camila Sousa; PRETTE, Almir Del; PRETTE, Zilda Aparecida Pereira Del. Qual o significado do trabalho para as pessoas com e sem deficiência física? Psico-USF, v.13, n.1, p.105-114, jan./jun. 2008

RICHARDSON, R. J. Pesquisa Social: métodos e técnicas. São Paulo: Atlas, 1999.

SANTANA, Leni de Lima et al. Absenteísmo por transtornos mentais em trabalhadores de saúde em um hospital no sul do Brasil. Rev. Gaúcha Enferm. Porto Alegre, v.37, n.1. 2016. Disponível em:

<http://www.scielo.br/scielo.php?script=sci_arttext\&pid=S198314472016000100416\&lng= en\&nrm=iso>. Acesso em: 04 nov. 2017. http://dx.doi.org/10.1590/1983-

1447.2016.01.53485.

SANTOS, Fernanda Batista Oliveira; FRANÇA, Montgomery Barroso. Fatores de risco para doença arterial coronariana em trabalhadores de enfermagem. Revista uruguaya de Enfermería (RUE), v.8, n.1, p.1-7, maio. 2013.

SILVA JUNIOR, João Silvestre; FISCHER, Frida Marina. Afastamento do trabalho por transtornos mentais e estressores psicossociais ocupacionais. Rev. bras. epidemiol. São Paulo, v.18, n.4, p.735-744, dez. 2015. Disponível em:

$<$ http://www.scielo.br/scielo.php?script=sci_arttext\&pid=S1415790X2015000400735\&lng= en\&nrm=iso>. Acesso em: 31 out. 2017. http://dx.doi.org/10.1590/1980-

5497201500040005.

SIME. Convenção coletiva de trabalho. Araçatuba, 2000. 